\title{
Interferon alfa-2b in mixed cryoglobulinaemia: a controlled crossover trial
}

C Ferri, E Marzo, G Longombardo, L La Civita, F Lombardini, D Giuggioli, R Vanacore, A M Liberati, A Mazzoni, F Greco, S Bombardieri

\begin{abstract}
To confirm the positive results of a preliminary trial, 26 patients with mixed cryoglobulinaemia were enrolled in a controlled, randomised, crossover trial with interferon alfa-2b. A significant improvement was seen in the purpura score and alanine aminotransferase activities during six months' treatment, and was associated with a significant decrease in cryocrit and a returning to normal of the lymphocyte CD4/CD8 ratio (in eight of nine patients). No significant variations were seen during the six month period without interferon. Only six patients withdrew from treatment, three because of side effects and three because of poor compliance.
\end{abstract}

(Gut 1993; supplement: S144-S145)

Mixed cryoglobulinaemia is an idiopathic lymphoproliferative disease with a variable number of visceral manifestations secondary to the tissue deposition of circulating immune complexes. The liver plays a part in the disease and chronic active hepatitis is a common complication occurring in about $70 \%$ of cases. The presence of hepatitis $\mathrm{C}$ virus (HCV)-RNA and anti-HCV antibodies in $90 \%$ of patients with mixed cryoglobulinaemia ${ }^{1-3}$ suggests that this virus may play an important pathogenetic part.

Treatment for mixed cryoglobulinaemia depends largely on the extent and severity of organ involvement in the disease. Steroid and plasma exchange or both, ${ }^{45}$ and a low antigen content $\operatorname{diet}^{6}$ have been used in a large series of patients with mixed cryoglobulinaemia. Interferon alfa-2b, an antiviral and immunomodulatory drug, has also been used in this disease with encouraging results. ${ }^{7}$ The aim of this controlled, randomised, crossover trial was to confirm the positive results of our preliminary study. ${ }^{8}$

\section{Patients and methods}

Twenty six patients with mixed cryoglobulinaemia ( 15 women and $11 \mathrm{men}$ ), with a mean age of 54 years ((6) SD) were entered into the study. Clinical and serological characteristics of the patients before treatment are shown in Table I.

All patients had six months without interferon alfa-2b (control period) and six months with interferon alfa-2b (INTRON A,
TABLE I Clinical and serological characteristics of 26 patients with mixed cryoglobulinaemia

\begin{tabular}{lc}
\hline Purpura & $23(88 \%)$ \\
Arthralgias & $24(92 \%)$ \\
Weakness & $25(96 \%)$ \\
Sjøgren's syndrome & $8(31 \%)$ \\
Raynaud's phenomenon & $4(15 \%)$ \\
Liver involvement & $19(73 \%)$ \\
Peripheral neuropathy & $20(77 \%)$ \\
Nephropathy & $1(4 \%)$ \\
Cryocrit \% (mean (SD)) & $5(9)$ \\
Cryo composition IgM (k) $\quad$ IgM (k+ $\lambda$ ) & $15(58 \%)$ \\
CH50 (normal >160 IU/l) (mean (SD)) & $11(42 \%)$ \\
C4 (normal >22 mg/dl) (mean (SD)) & $83(75)$ \\
Antinuclear antibodies & $11(10)$ \\
Anti-smooth muscle antibodies & $1(4 \%)$ \\
Antimitochondrial antibodies & $4(15 \%)$ \\
anti-HCV positive & $1(4 \%)$ \\
HCV-RNA (polymerase chain reaction positive) $\ddagger$ & $24(96 \%)$ \\
\hline
\end{tabular}

$\star$ On the basis of increased serum alanine aminotransferase activities and histological alterations, or both.

†Determined by second generation ELISA and RIBA (Chiron).

$\ddagger 22$ patients tested.

Schering-Plough Corporation) at a dose of 2 million units (MU) daily for one month by subcutaneous injection, then every other day for five months. For those patients who started the trial on alfa- $2 b$ treatment, a one month washout period was included before the second half of the study. The low to medium steroid dosages prescribed before treatment 6-methylprednisolone; 4-8 mg/day) continued unchanged.

\section{Results}

During interferon alfa-2b treatment, a statistically significant improvement was seen using Wilcoxon's non-parametric test in the purpura score and in serum alanine aminotransferase activities (Table II). Clinical results were also reflected by changes in immunological parameters: cryocrit decreased

TABLE II Changes in purpura score, serum alanine aminotransferase $(A L T)$ activities, and cryocrit in treated and untreated patients

\begin{tabular}{|c|c|c|c|c|}
\hline & \multicolumn{2}{|l|}{ Treated } & \multicolumn{2}{|l|}{ Untreated } \\
\hline & Before & After & Before & After \\
\hline Purpura score & $\begin{array}{c}1 \cdot 6(0 \cdot 3) \\
\mathrm{p}<0\end{array}$ & $\begin{array}{l}0 \cdot 3(0 \cdot 2) \\
01\end{array}$ & $1.7(0.3) \mathrm{N}$ & $1.4(0.3)$ \\
\hline $\begin{array}{l}\text { Serum } \\
\text { ALT }(\times \text { ULN })\end{array}$ & $2.5(0.5)$ & $1.5(0.2)$ & $2 \cdot 6(0 \cdot 7)$ & $2 \cdot 2(0.4)$ \\
\hline Cryocrit \% & $\begin{array}{r}5.6(2 \cdot 4) \\
p<0\end{array}$ & $\begin{array}{l}3 \cdot 0(1 \cdot 8) \\
02\end{array}$ & $4 \cdot 1(2 \cdot 2)$ & $3.5(1.7)$ \\
\hline
\end{tabular}

All values are mean (SEM). 
significantly and lymphocyte CD4/CD8 ratio returned to within normal limits in eight of nine patients. In contrast, no significant variations were seen during the six month period without interferon. Only six patients withdrew from the trial: three because of side effects and three because of poor compliance.

\section{Conclusions}

These results confirm the efficacy of interferon alfa-2b, particularly for purpura and liver involvement in mixed cryoglobulinaemia. As HCV seems to be responsible for the immunological disorder in mixed cryoglobulinaemia, the use of interferon, an antiviral drug, can be considered a possible treatment for this condition.
1 Ferri C, Greco F, Longombardo G, et al. Antibodies to hepatitis $\mathrm{C}$ virus in patients with mixed cryoglobulinemia. Arthritis Rheum 1991; 34: 1606-10.

2 Ferri C, Greco F, Longombardo G, et al. Antibodies against hepatitis $\mathrm{C}$ virus in mixed cryoglobulinemia. Infection 1991; 19: 417-20.

3 Ferri C, Greco F, Longombardo G, et al. Association between hepatitis $\mathrm{C}$ virus and mixed cryoglobulinemia. Clin Exp Rheumatol 1991; 9: 621-4.

4 Ferri C, Moriconi L, Gremignai G, et al. Treatment of the renal involvement in mixed cryoglobulinemia with prolonged plasma exchange. Nephron 1986; 43: 246-53.

5 Ferri C, Gremignai G, Bombardieri S, et al. Plasma exchange in mixed cryoglobulinemia. Effects of renal, liver and neurologic involvement. Ric Clin Lab 1986; 16: 403-11.

6 Ferri C, Pietrogrande M, Cecchetti R, et al. Low-antigencontent diet in the treatment of patients with mixed cryoglobulinemia. Am f Med 1989; 87: 519-24.

7 Casato M, Lagana B, Antonelli G, Dianzani F, Bonomo L. Long-term results of therapy with interferon-alpha for type II essential mixed cryoglobulinemia. Blood 1991; 78: 3142-7.

8 Ferri C, Marzo E, Longombardo G, Lombardini F, Greco F, Bombardieri S. Alpha interferon in the treatment of mixed cryoglobulinaemia patients. Eur $\mathcal{F}$ Cancer 1991; 27 (suppl 4): S81-2. 